\title{
The Cloudless Effect Evaluation for Hourly Irradiance in Turkey
}

\author{
Z. ER*, O. Derici, I.B. Turna, B. Karatas, M. Eroglu and E. Alyanak \\ Istanbul Technical University, Faculty of Science and Letters, Physics Engineering Department (13b), 34469 \\ Istanbul, Turkey
}

\begin{abstract}
There are several ways to predict and/or estimate solar radiation in a particular defined area. It is important to model and design the efficiency of solar systems such as time series, solar radiation data. The time series data are significant for performance prediction and other purposes. The solar radiation data which belong to the defined location are not always available. In this study, it is investigated that how affected hourly solar radiation value under conditions of cloudiness. The methods in the literature are based on a decomposition model that calculates solar radiation components related to atmospheric transmittance. This study aims to evaluate the hourly irradiance by added effect of cloudiness on calculations for Turkey. While a decision matrix was used in several methods, the regression correlation of meteorological parameters was used in the other methods. In addition, the API application program is created by Java programming language. This enables users to obtain solar radiation for getting data, processing, extracting meaningful result and making these processes respectively where they are. The results show that the climate variables, air temperature, and solar radiation were highly correlated to transpiration.
\end{abstract}

DOI: 10.12693/APhysPolA.134.391

PACS/topics: photovoltaic (PV), solar radiation, solar irradiance, hourly irradiance, relative weather cloudless

\section{Introduction}

Skipping the basic background estimation and calculation can be a bit time-consuming at the beginning of the design process, but there is a great cost-benefit in the long run. The related calculations appear to be sufficient to discriminate each station from the others due to the local characteristic of the defined regions. The methods for calculating solar energy from meteorological data require various climatological and physical parameters. Some of the data are measured directly in weather stations. Other parameters are related to commonly measured data and can be derived with the help of a direct or empirical relationship. On the other hand, the models that have been determined to estimate solar irradiance on the horizontal surfaces can be classified into two types as parametric models and decomposition models. The decomposition models are based on a correlation that this correlation is defined as a function of the hourly clearness index [ratio of hourly global horizontal $\left(I_{H}\right)$ to hourly extraterrestrial radiation $\left.\left(I_{0}\right)\right]$ such in this study.

\section{Materials and methods}

The first need is to estimate the position of the sun. There is a relationship between the presence of cloud and humidity level in meteorological forecasting. The formula to calculate relative humidity is

$$
R_{H}=\frac{\rho_{w}}{\rho_{0}} 100 \%
$$

where $R_{H}$ is relative humidity, $\rho_{0}$ is density of water va-

\footnotetext{
*corresponding author; e-mail: erzuh@itu.edu.tr
}

por, and $\rho_{w}$ is density of water vapor at saturation $[1,2]$. The clearness index $\left(k_{t}\right)$ is a random parameter that varies according to time of the year, season, and geographical situation of a defined location. In the literature, we can find a lot of model studies to estimate or define the solar irradiance. In this paper we consider several models which are more accurate model for Istanbul. To find the most suitable model for Istanbul, the effect of cloud on solar irradiance is compared with the article by Kasten and Czeplak [3]. The most important numerous solar radiation numerical method is the correlation that is proposed by Angstrom depending on the monthly average clear sky daily total radiation on horizontal surface $(H)$ for a given location. Prescott has modified the Angstrom method by depending on extraterrestrial radiation instead of clear sky daily radiation as given in Eqs. (2), (3). The monthly average daily extraterrestrial radiation on the horizontal surface is formalized with Eq. (3) $[1,3-9]$ :

$$
\begin{aligned}
& \frac{H}{H_{0}}=a+b\left(\frac{S}{S_{0}}\right) \\
& H_{0}=(24 / \pi) I_{s c}[1+0.033 \cos (360 n / 365)] \\
& \quad \times\left[\cos (\phi) \cos (\delta) \sin \left(w_{s}\right)+\pi / 180 w_{s} \sin (\phi) \sin (\delta)\right],
\end{aligned}
$$

where $a$ and $b$ are empirical constants; $S$ is the monthly average daily hours of bright sunshine; $S_{0}$ is the monthly average of the maximum possible daily hours of bright sunshine i.e., the day length represented by $n$ of the average day of the month; $\omega_{s}$ is the sun set hour angle in degrees; $\varphi$ is the latitude, the angular location north or south of the equator; $\delta$ is the angular position of the sun at solar noon, called declination as shown in Eqs. (4),(5). Besides, the mentioned equation also depends on the rel- 
ative sunshine duration where the monthly average maximum possible daily sunshine duration can be defined due to the mean sunset/sunrise hour angle as shown in the following equation:

$$
S_{0}=\frac{2}{15} w_{s}
$$

Moreover, the monthly average maximum possible daily sunshine duration can be computed according to the latitude and the solar declination angle

$$
S_{0}=\frac{2}{15} \cos ^{-1}(-\tan \phi \tan \delta)
$$

The web page open free data via worldweatheronline.com /istanbul-weather-history/istanbul/tr.aspx was used in this study for the result evaluation in May 2017, taken into consideration in Istanbul.

\section{Results and discussion}

This study investigated the changes in the clearness index, global solar radiation by applying for open days in Istanbul, Turkey. There are several models to estimate or defined the solar radiance due to the locations. The calculation results via the models for Istanbul are illustrated in Fig. 1. These tested models include both the debilitating effect of the atmosphere and the cloud effect. Below evaluations consist the atmospheric effect only in cloudless conditions. Therefore, these evaluations comprise that it needs to reveal how the amount of change in the clearness index is to be obtained with the debilitating effect of the atmosphere of the components. In this point, Kasten and Czeplak determined that global hemispherical irradiance on a horizontal surface as a function of cloud amount $N$ (eighths) is given by Eq. (6):

$$
G(N)=G(0)\left(1-0.75(N / 8)^{3.4}\right)
$$

$G(N)$ is global hemispherical irradiance on a horizontal surface (GHI) as function of cloud amount $N$. G(0) is clear sky GHI. The clear sky value $G(0)$ depends on solar elevation angle as mentioned in the below. Under cloudy conditions, the cloudless-sky solar irradiance can be estimated by some uncertainties resulting from solar radiation transfer model calculations or extrapolations. The index proposed by Perez et al. has been used

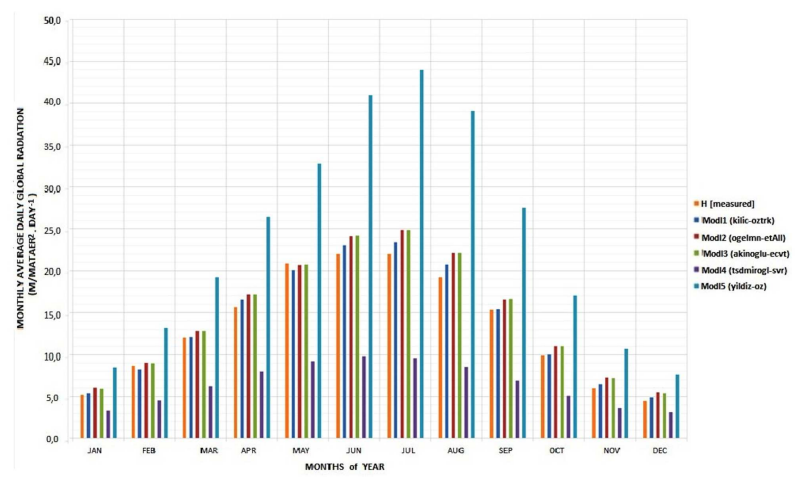

Fig. 1. Calculation evaluation for Istanbul within the model correlations. for that aim. The normalized clearness index defined as Eq. (7) $[1,2]$ :

$$
k_{t}^{\prime}=\frac{k_{t}}{1.031 \exp \left(\frac{-T_{L}}{0.9+9.4 / M}\right)+0,1}
$$

where $T_{L}$ is the Linke turbidity parameter, $M$ is the relative air mass given by Kasten [1] and $k_{t}$ is the clearness index, defined as the ratio between horizontal irradiance reaching the earth surface $\left(I_{H}\right)$ and the extraterrestrial solar irradiance at normal incidence $\left(I_{0}=1367 \mathrm{~W} \mathrm{~m}^{-2}\right)$ on the horizontal surface, Eqs. (8)-(10). This index measures the attenuation that the radiation suffers when it passes through the atmosphere

$$
\begin{aligned}
& k_{t}=I_{H} / I_{0}, \\
& m=1 / \cos \theta_{z}, \\
& T_{L}=-\left[\left(1 / m\left(0.00897 \lambda^{-4.09}\right)\right)\left(\ln \left(I_{\lambda} S / I_{0 \lambda}\right)\right)\right]
\end{aligned}
$$

where $S$ is a factor that accounts for the Sun-Earth distance variation in astronomical units. The Linke turbidity factor $T_{L}$ can be derived from pyrheliometric measurements. The wavelengths $\lambda=0.38 \mu \mathrm{m}$ and $\lambda=0.5 \mu \mathrm{m}$ are generally used to get the optimum optical thickness of the aerosol [10]. The model comprises a simple exponential correlation. Calculation results are given by Fig. 2.

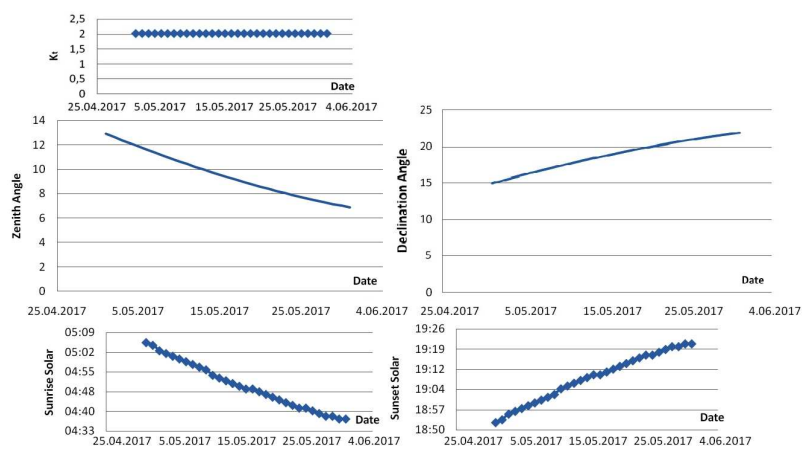

Fig. 2. Summary of the parametric model for Istanbul region in Turkey for pure Rayleigh atmosphere.

These calculated values due to Eq. (6) and Eq. (7) are also checked with the weather conditions for Istanbul in May 2017 with real data which are from open free data of web page of world weather online as Figs. 3, 4 and Table I, respectively.

As shown in Fig. 3, the UV index of Istanbul due to the months depends on the seasons and weather conditions. The UV index in May for Istanbul changes value between 7.4 (2016) and 5.4 (2015) as we accepted. In this point, it can be compared with distribution of average cloud humidity in Istanbul as shown in Fig. 4. The visibility distributions are also given by Fig. 4 as supported by the results. 
Chemical compositions of AISI 304 austenitic and AISI 420 martensitic stainless steels

TABLE I

\begin{tabular}{c|c|c|c|c|c|c|c|c}
\hline \hline Date & Weather & Max. temp. & Min. temp. & Wind & Precipitation & Humidity & Pressure & Cloud cover \\
\hline 2009 & sunny & $22^{\circ} \mathrm{C}$ & $13^{\circ} \mathrm{C}$ & $10 \mathrm{mph} \mathrm{NE}$ & $0.0 \mathrm{~mm}$ & $64 \%$ & $1019 \mathrm{mb}$ & $6 \%$ \\
2010 & sunny & $33^{\circ} \mathrm{C}$ & $18^{\circ} \mathrm{C}$ & $5 \mathrm{mph} \mathrm{W}$ & $0.0 \mathrm{~mm}$ & $51 \%$ & $1012 \mathrm{mb}$ & $1 \%$ \\
2011 & sunny & $21^{\circ} \mathrm{C}$ & $17^{\circ} \mathrm{C}$ & $18 \mathrm{mph} \mathrm{NE}$ & $0.0 \mathrm{~mm}$ & $86 \%$ & $1015 \mathrm{mb}$ & $33 \%$ \\
2012 & sunny & $23^{\circ} \mathrm{C}$ & $18^{\circ} \mathrm{C}$ & $11 \mathrm{mph} \mathrm{NE}$ & $0.1 \mathrm{~mm}$ & $80 \%$ & $1013 \mathrm{mb}$ & $11 \%$ \\
2013 & sunny & $25^{\circ} \mathrm{C}$ & $20^{\circ} \mathrm{C}$ & $11 \mathrm{mph} \mathrm{WSW}$ & $0.6 \mathrm{~mm}$ & $67 \%$ & $1013 \mathrm{mb}$ & $3 \%$ \\
2014 & sunny & $29^{\circ} \mathrm{C}$ & $23^{\circ} \mathrm{C}$ & $4 \mathrm{mph} \mathrm{WSW}$ & $0.3 \mathrm{~mm}$ & $68 \%$ & $1010 \mathrm{mb}$ & $9 \%$ \\
2015 & thundery & $30^{\circ} \mathrm{C}$ & $26^{\circ} \mathrm{C}$ & $7 \mathrm{mph} \mathrm{SW}$ & $1.8 \mathrm{~mm}$ & $64 \%$ & $1007 \mathrm{mb}$ & $19 \%$ \\
2016 & light rains & $21^{\circ} \mathrm{C}$ & $19^{\circ} \mathrm{C}$ & $10 \mathrm{mph} \mathrm{NNW}$ & $16.1 \mathrm{~mm}$ & $78 \%$ & $1013 \mathrm{mb}$ & $38 \%$ \\
2017 & sunny & $23^{\circ} \mathrm{C}$ & $20^{\circ} \mathrm{C}$ & $13 \mathrm{mph} \mathrm{NE}$ & $0.3 \mathrm{~mm}$ & $73 \%$ & $1013 \mathrm{mb}$ & $18 \%$
\end{tabular}

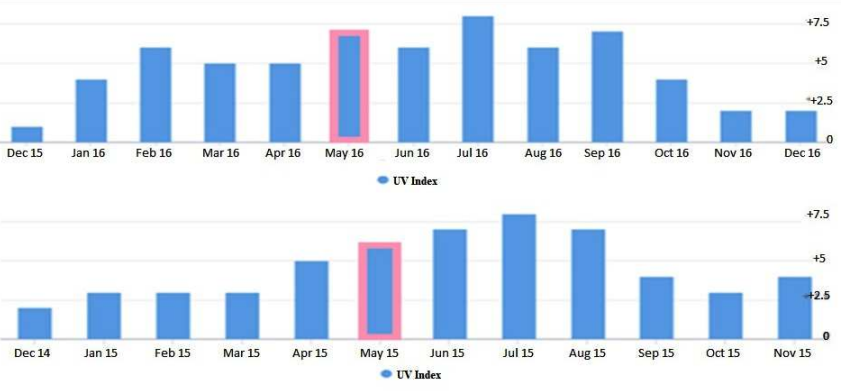

Fig. 3. Historical UV index in Istanbul, Turkey.

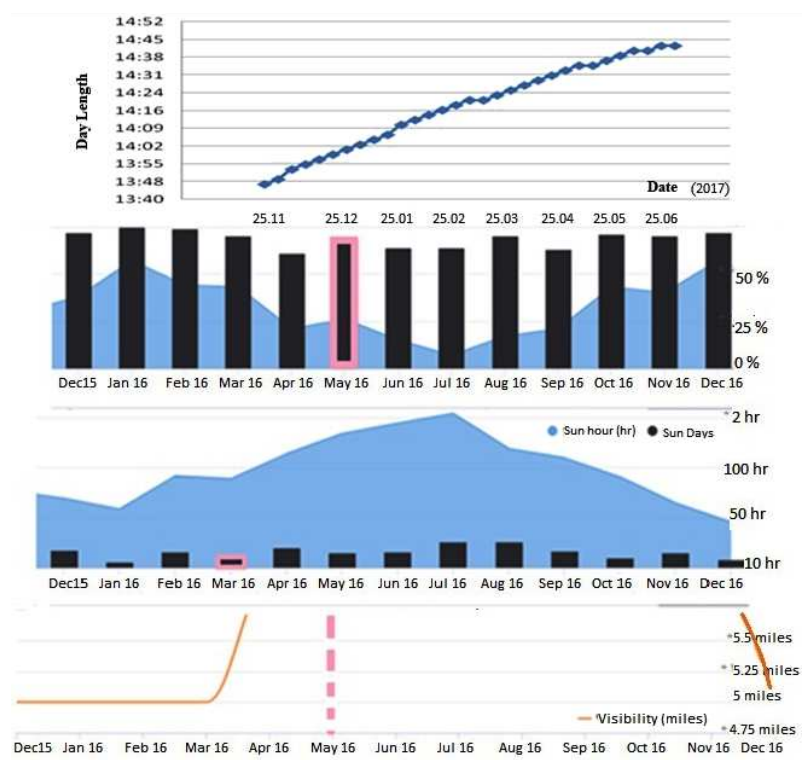

Fig. 4. Average cloud and humidity, average sun hour and sun days, average visibility in Istanbul, Turkey.

It is clearly seen that May season for Istanbul is under the pure Rayleigh atmosphere condition. This study results give evaluation of sun set and sun rise evaluations for the aim of control of the results. Therefore these control parameters are checked with the average sun hour and sun days.

\section{Conclusion}

This study represents that if skies are clear, more heat reaches the earth surface. This leads to warmer temperatures. However, if skies are cloudy, some of the sun rays are reflected off the cloud droplets back into space. Therefore, less of the sun energy is able to reach the earth surface, which causes the earth to heat up more slowly. This leads to cooler temperatures. The agreement between the calculated and estimated values is remarkable and it is recommended for use in any location in Turkey or stations with similar climate. With this study, the issue of cloudless effect for solar irradiance is considered by aspects as investigation of solar energy sector and establishment of Turkey profile. This study is reflected that the dominated factors such as cloudless effects have been identified in the atmosphere, incoming solar radiation is much more effective than on the predictions.

\section{References}

[1] G. Sánchez, A. Serrano, M.L. Cancillo, Opt. Pure Appl. 45, 33 (2012).

[2] Effects of Cloud Cover, University of Illinois, WW2010.

[3] F. Kasten, G. Czeplak, Solar Energy 24, 177 (1980).

[4] Z. Er, Acta Phys. Pol. A 128, B300 (2015).

[5] Z. Er, Acta Phys. Pol. A 128, B477 (2015).

[6] Z. Er, Acta Phys. Pol. A 130, 72 (2016).

[7] I.B. Turna, M.Sc. Thesis, Istanbul Technical University, 2015.

[8] A. Angström, Quart. J. Roy. Meteorol. Soc. 50, 121 (1924).

[9] A.A. Jadaalah, Z. Er, D.Y. Mahmood, Z.A. Abdulqaedr, Acta Phys. Pol. A 130, 434 (2016).

[10] U.A. Rahoma, A.H. Hassan, Am. J. Environ. Sci. 8, 597 (2012). 